\title{
Design of Crane Safety Monitoring System Based on Big Data Analysis
}

\author{
Wang Guo -liang ${ }^{1 . a}$, Cheng Xian-yi ${ }^{1, b}$, Li Ji-yao ${ }^{1, c}$ and Qu Ping ${ }^{2, d}$ \\ ${ }^{1}$ School of Computer Science and technology, Nantong University, Nantong 226019 \\ ${ }^{2 .}$ Cheento(Beijing) information technology co., LTD, 100080,China \\ a1786374738.qq.com,bxycheng@ntu.edu.cn,c25594452@qq.com ,d.12237139@qq.com
}

Keywords: Tower crane. Big data. Safety monitoring

\begin{abstract}
Aiming at the problems of tower crane safety performance assessment and prediction, put forward a scheme of tower crane safety monitoring based on large data analysis, this scheme provides a three-level architecture. Rank field by field data acquisition unit is responsible for collecting various operation parameters of tower crane, and on the basis of collection of various parameters on site using industrial-grade touch screen real-time display, analysis and early warning, provide data support for a line of the pilot; And departmental monitoring service can be gathered from the jurisdiction of all operation parameters of tower crane, provide data support for the management regulatory decisions, in the departmental service regulators can be via computer terminals and smartphone mobile terminal to realize the remote supervision is responsible for all kinds of tower crane; Center stage, through the large data analysis platform gathers various departments supervision server monitoring data, provide data support for the decision-making management decision-making management. On-site test show that the proposed scheme on tower crane safety performance assessment, prediction has certain advantage.
\end{abstract}

\section{1、Introduction}

Due to the crane lifting height, large in range, high work efficiency, light structure, and convenient disassembly and assembly and convenient transportation advantages, has been widely used in construction sites, bridges, ports, water conservancy and electric power, and other types of cranes, the operating mechanism can generally be repeated, short-term, intermittent work mode. The tower crane structure in addition to withstand the weight and work load, but also bear the inertia and momentum for an additional role, mainly by parts for a long time by larger compression, bending, torsion, and repeated loading effect, easy fatigue caused by damage to the overall instability, the accident. In China's tower crane is listed as special equipment, is a greater risk of equipment, and its service life there has been no standard ${ }^{[1]}$, so tower crane on the construction site of the intelligent security management has become the trend of the development of the industry.

In recent years, with the rapid development of artificial intelligence and big data analysis technology. Embedded system toward the all-digital and intelligent direction, and the traditional embedded system compared, based on the data analysis of the embedded system can produce high-level semantic understanding from the original of the underlying collection of sensor data, can produce to the monitored object behavior analysis, is unmatched by traditional embedded system has become important part of security technology to prevent the system extremely ${ }^{[2]}$. 


\section{2、 System design}

System architecture. Based on the data analysis of the tower crane safety monitoring system refers to from the foundation design of tower crane, crane completely defused by using life cycle, means of Internet technology and data analysis through the tower crane safety record management, tower foundation design and construction plan, crane operation monitoring and recording a set of safety monitoring and management system ${ }^{[3]}$.

System uses three layer architecture (see Figure 1), layer 1 for the field level, is responsible for the acquisition of tower crane operation card, wind direction, wind speed, drop weight, torque, tilt angle; the layer 2 Department, responsible for coordination in the same site on the tower crane sensor data; layer 3 center, responsible for the analysis between the same parameters, different site, different regions, the same brand or a different brand, equipment operation state and tendency to develop more optimal safety precaution scheme.

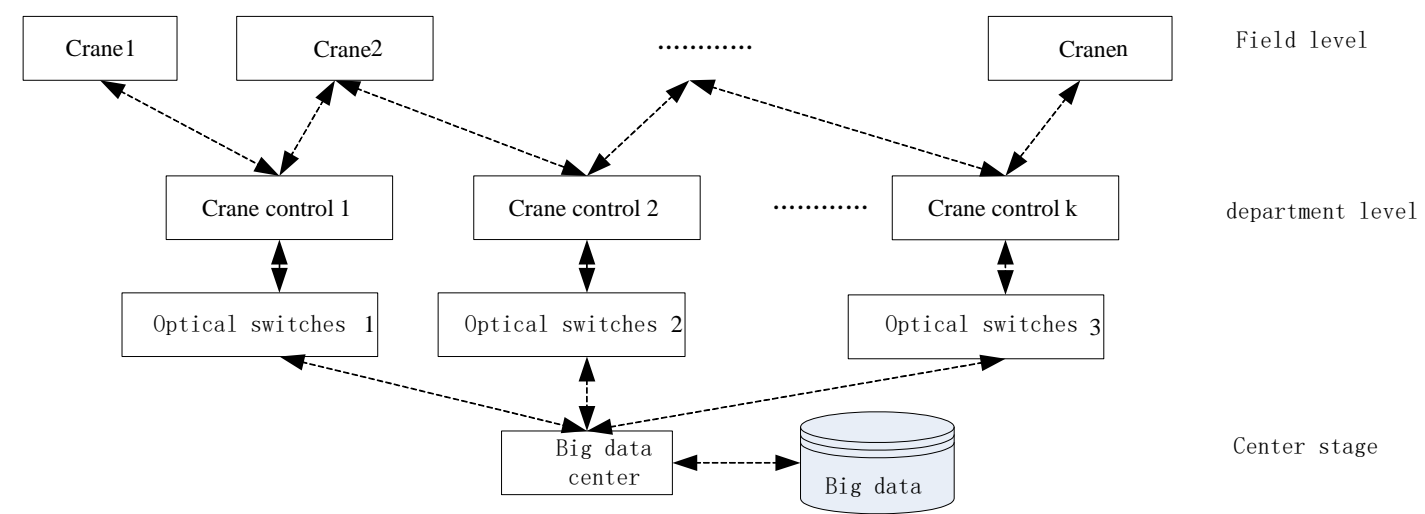

Figure 1 crane safety monitoring system of three layer structure

\section{Software design.}

Project office monitoring software design. Project Office monitoring software is an important part of the whole monitoring system. Tower crane side console in the collection to the real-time operation of tower crane like information, according to need to start the GPRS wireless transmission, data real-time, timely, or on-demand replication to control room side, to perfect the system of tower crane safety monitoring data of follow-up treatment, backup and analysis of processing functions. Downloaded from the side of the tower crane information stored in the authentication of the user's PC database, to the authenticity and reliability of the protection of data information, the database does not allow non users of the system software for access and user software according to different users with different permissions, awarded the appropriate permissions to the software function, the monitoring software relates to the software interface development, user authentication, the backstage database connecting large data centers ${ }^{[4]}$.

Analysis software design for large data center. The tasks of the big data centers are statistics, prediction and visualization. Acquisition to the original data source just some basic data, contains a lot of noise, most of the data no semantic; information is the data annotated with semantic; knowledge is the integration of information, expression of the certain theme, knowledge is divided into quantitative and qualitative knowledge; knowledge ranging from to solve the problem, through the knowledge to solve practical problems it is wisdom.

$\mathrm{R}$ language is a kind of excellent data analysis language with strong data visualization function. This project uses the $\mathrm{R}$ language to achieve the task of large data centers ${ }^{[5]}$.

The software structure is shown in figure 2. 


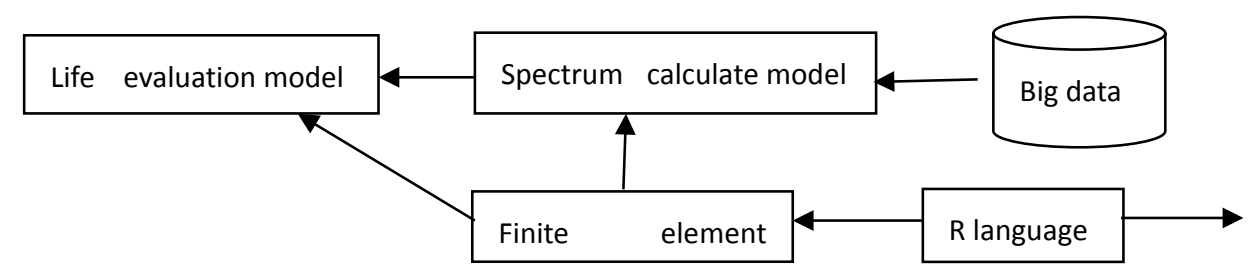

visualization

Figure 2 data analysis software structure

The crane controller design. Operation of the crane hardware monitoring integrated using microelectronic technology, sensor technology and timely communication technology, the main safety device of the crane, including torque limiter, weight limiter, amplitude limit a device, rotary limit position and height limiter the operating data collection, record and storage. Including crane load monitor, tower crane anti-collision monitor the tower and the regional protection monitor three kinds of instrument and equipment, mainly used for horizontal arm and the movable arm two kinds of tower crane, the user can choose according to the actual needs of the project.

Controller of the tower crane can be the operation data recording, storage and real-time display, the gravity torque, weight, the amplitude, the rotating angle and allow a high degree of control and early warning, to achieve synchronous remote monitoring. Mainly include the following program:

Force and torque monitoring to prevent overload solution. Installation of intelligent torque monitoring equipment, automatic acquisition of each weight;

The installation of the display screen, real-time display of each weight, the driver can be seen at any time;

When the crane overload, sound and light warning system automatically, when the weight is greater than the corresponding gear allows the rated value, the system will automatically cut off the power supply rise, allowing only the descent direction movement;

The tower crane each data are through GPRS module to send real-time monitoring system, remote synchronization monitoring.

Tower operation monitoring, to prevent the collision solution. Tower cranes per tower are installed anti-collision monitoring equipment, real-time monitoring of the tower crane working condition (angle, radius, etc.), crane intelligent identification and judgment of risk of collision region;

The arm into the dangerous area of collision, the system began to sound and light warning, the closer, alarm and more anxious, a timely reminder of the crane driver to stop dangerous direction.

Specific area monitoring to prevent falling objects wounding solution. Install regional protection and monitoring device, set the working area of crane, intelligent control to a specific region of the big arm banned to achieve regional protection.

Safety special preparation to prevent accidents solutions. Through professional software intelligent drawing tower crane safety dismantling safety special programs, to ensure that the design and calculation of compliance with the requirements of the code and informative programs, to operate.

The tower and attached tower crane design, prevent overturning solution. Through the professional software of tower crane foundation and attached to the intelligent design calculation to ensure scientific design, reasonable calculation, can meet the requirements of relevant codes and standards, and guide the construction.

Equipped with smart cards, to achieve human-computer management. By the crane monitoring system platform, for tower crane implement online filing management, full range 
remote management of tower crane installation, disassembly and replacement; through the implementation of IC card, real name system management of crane driver, effective supervision.

\section{System operation test}

The device status evaluation results are shown in figure 3.

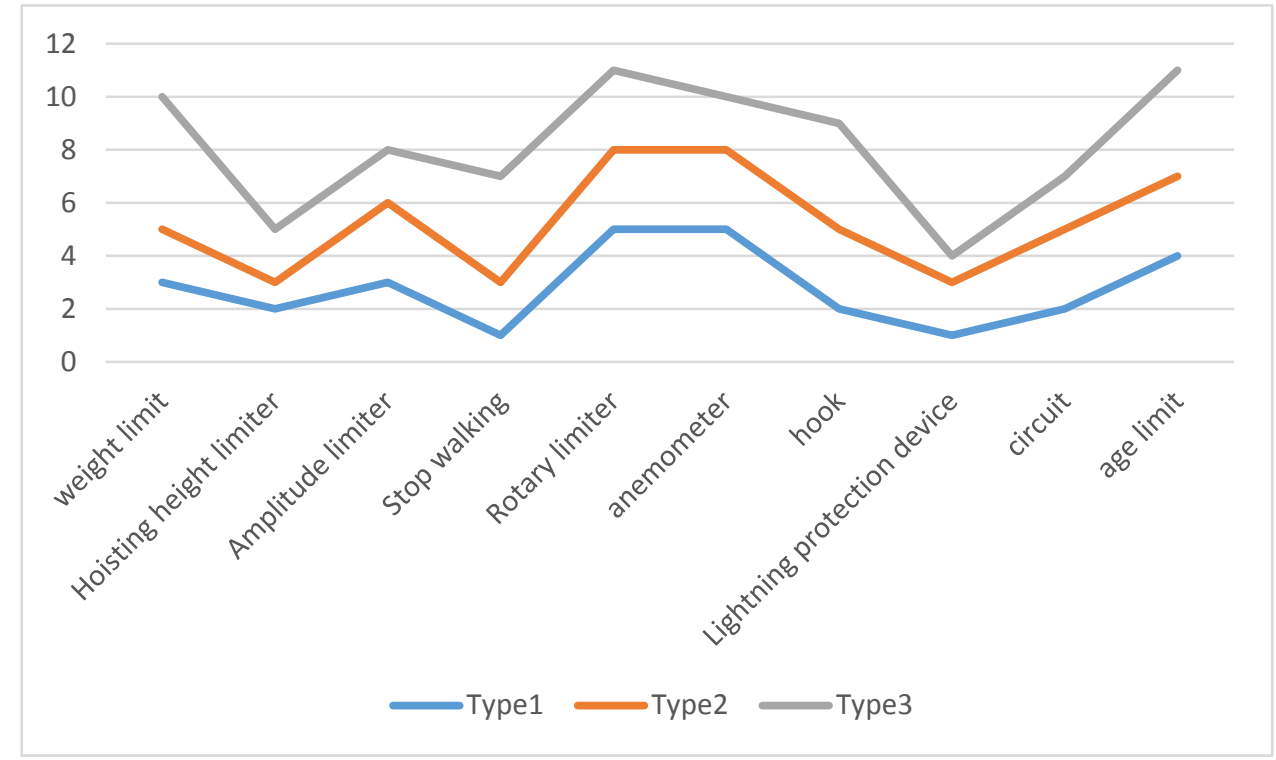

Figure 3 center stage equipment transfer assessment results screenshot

\section{Concluding remarks}

Based on data analysis of tower crane whole process safety supervision and management system, the mechanical safety device into data, all safety devices and operation apparatus can be concentrated to a large data operation platform, using the unit operation of real-time monitoring of tower crane, intensify management, strict law enforcement basis are provided for the tower crane, the relevant units, and supervision of operation and command personnel improve safety awareness and reduce or eliminate safety hidden danger of accident; on the other hand, timely early warning function and timely remind the operator to prevent unexpected security risks.

\section{Acknowledgment}

This research was financially supported by the projects of University-enterprise cooperation of College students' training in Jiangsu

\section{References}

[1]Shi Hong Bao. Service lives of tower crane and evaluation of [J]. Construction machinery technology and management, 2008, (5): 130-136.(china)

[2] Wu Xuesong. Review and Prospect of China tower crane market for 50 years. Building, 2008, (04): 67 - 65(china)

[3] Huang Hongzhong, Yao Xinsheng. Review of tower crane safety, construction safety, 2001 (3): 26-31. (china) 
[4] visualization, Baidu Encyclopedia [EB/OL].[2015-07-05.http://baike.baidu.com, 2015

[5]Cbang Winston (Xiao Nan, Deng Yishuo, Wei Taiyun).R data visualization Handbook [M]. Beijing: People's Posts and Telecommunications Publishing House, 2015 (Chinese version). 